\title{
The Production of Penicillin in Wartime China and Sino-American Definitions of "Normal" Microbiology"
}

\author{
Mary Brazelton \\ mab94@cam.ac.uk \\ Department of History and Philosophy of Science, Cambridge University, Cambridge
}

\begin{abstract}
This article discusses the history of domestic penicillin production in China during the Second Sino-Japanese War, focusing on the work of the National Epidemic Prevention Bureau (NEPB) to identify, isolate, cultivate, and extract the drug. This work took place just as the American Bureau for Medical Aid to China discussed plans to establish an American pilot plant for Chinese penicillin manufacture, which would directly transfer technologies and personnel from the United States to China. While American advisers saw the basic conditions of wartime China as actively obstructing the highly technical project of penicillin production, researchers at the NEPB relied crucially upon that same local environment to identify useful molds and find substitutions for key materials in successfully manufacturing penicillin in Kunming, capital of Yunnan Province in southwest China.
\end{abstract}

Keywords: penicillin; antibiotic; medicine; World War II; American Bureau for Medical Aid to China; National Epidemic Prevention Bureau; Tong Cun; Tang Feifan

On December 14, 1945, a one-year-old infant with the initials YTM was admitted to the Shanghai Public Hospital for Children. The boy had had a fever and cough for over two weeks, and initial treatment with sulfonamides - the first antibiotics and global wonder drugs of the 1940s — had resolved the former complaint, but not the latter. Upon his admission to hospital, physical examination revealed "a child, fairly well-developed, under-nourished, dyspneic [having difficulty breathing] and cyanotic [with skin tinged blue due to tissues near the skin surface having low oxygen saturation]." The child's chest bulged on the left side, and examination with X-ray methods of fluoroscopy revealed that this was due to fluid in the tissues. A procedure to remove fluid from the lungs produced 150 cubic centimeters of "thick pus" that tested positive for pneumococcus, the bacterium that causes pneumonia. ${ }^{1}$

Before December 1945, such cases of empyema, or fluid in the pleural cavity typically due to pneumonic infection, were often mortal for young patients. The only available treatment consisted of surgical interventions with such high levels of risk that many surgeons

\footnotetext{
${ }^{1}$ Lin Shujin, "Penicillin in the Treatment of Empyema," 74. The case study is described as commencing on December 14, 1946, but since the article was published in March/April 1946, the note must be an error and actually refers to 1945. The other cases described all happened in December 1945 and January 1946.
} 
were not willing to attempt them on children. But in April 1946, Lin Shujin, resident physician at the Shanghai Public Hospital for Children, gave a paper to the Chinese Pediatric Society and the Chinese Medical Association that revealed a chemotherapeutic alternative. Five days after the young YTM was admitted to hospital, he was given penicillin (qingmeisu, or alternatively pannixilin). After a combination of intrapleural and intramuscular administration totalling 580,000 Oxford units of penicillin for ten days, "the patient's general condition improved markedly during treatment.",2 After discussing a number of other similar case studies, Lin concluded that compared with surgical interventions or treatment with sulfonamides, "penicillin therapy is definitely superior for the treatment of empyema in pediatric practice." 3

This paper was just one of the many studies that emerged at the end of the Second Sino-Japanese War which discussed the potential of penicillin, a drug produced from the fungus Penicillium notatum, as a therapeutic agent in glowing terms. The medicine's potential was all the more exciting given the catastrophe that epidemic disease had wrought during the war years. By 1938, just one year after the outbreak of conflict with Japan, cholera had ravaged Hubei, Hunan, and Jiangxi Provinces, and relapsing fever had spread across northwest China. The malarial diseases traditionally associated with southern and southwestern China also reared their heads in those regions. ${ }^{4}$ In 1939 the plague struck Yunnan, and in 1942 a cholera outbreak ravaged the province. Wartime migrations of soldiers and refugees only facilitated the spread of such diseases across China's interior. ${ }^{5}$ In 1943 Jin Baoshan, the wartime head of the National Health Administration (Weishengshu), noted that plague and cholera were the most serious epidemic threats facing the nation, and "under war

\footnotetext{
${ }^{2}$ Lin Shujin, "Penicillin in the Treatment of Empyema," 75. An Oxford unit of penicillin referred to a standard unit of potency for the drug, as defined by its ability to prevent the growth of the bacterium Staphylococcus aureus, and calibrated against samples of penicillin distributed from the Oxford laboratory where the standard had been developed.

${ }^{3}$ Lin Shujin, "Penicillin in the Treatment of Empyema," 84.

${ }^{4}$ Yip, "Disease and the Fighting Men," 174; Bello, "To Go Where No Han Could Go."

${ }^{5}$ Yip, "Disease and the Fighting Men," 174.
} 
conditions there have been serious outbreaks of typhus fever and relapsing fever among the soldiers and refugees." ${ }^{\prime 6}$ In such dire conditions, the promise of a drug like penicillin that could quickly resolve a variety of infections was a godsend.

Lin did not discuss the source of the drug used at Shanghai Public Hospital for Children. Yet the establishment of penicillin as a therapeutic drug in China was a remarkable event, one with origins in the Second Sino-Japanese War that had concluded just a year earlier. The first drugs arrived in China from the United States in August 1944 as a result of the Lend-Lease Act, the American program to support Allied nations by sending them material aid in the form of food, weapons, fuel, and other items necessary for the machinery of war. ${ }^{7}$ The regular domestic production of penicillin in China, by Chinese bacteriologists, was another matter altogether. It relied on the wartime work of a small unit with temporary headquarters in remote Yunnan province, the National Epidemic Prevention Bureau (NEPB). This article discusses the history of domestic penicillin production in China, focusing on the wartime efforts of the NEPB in Kunming to isolate antibacterial mold strains and develop them as viable therapeutic drugs despite a number of logistical and theoretical challenges. In contrast to narratives that place American institutions, tools, and people at the center of global histories of penicillin manufacture, Tang Feifan and the NEPB developed the capacity to produce small amounts of penicillin without access to the equipment, raw materials, or strains that were thought to be necessary to such a project. The establishment of penicillin in China might seem at first blush to be anything but ordinary, given that its agents have been praised as pioneers of medical science who inaugurated a new age of pharmaceutical development in China. ${ }^{8}$ Their work indeed laid the foundations for penicillin to become a significant and widely used drug in China. Over subsequent decades, its

\footnotetext{
${ }^{6}$ King, "Epidemic Prevention and Control in China," 51.

${ }^{7}$ Preliminary Report of the Central Penicillin Control Committee with Special Reference to the Activities of the Subcommittee for Civilians, January 25, 1945, p. 1, Archives of the American Bureau for Medical Aid to China, box 24

${ }^{8}$ Xu Dingding, "Kangri zhanzheng shiqi," 357.
} 
employment became so common that antibiotic-resistant bacteria now pose a major threat to public health in East Asia. Moreover, negotiations in the 1940s over how to transfer technologies of penicillin production from the United States to China revealed tensions over the conditions of normal, everyday life in China - and the extent to which these conditions were not considered to be compatible with the technologically complex production of penicillin.

Exchanges between NEPB researchers, Chinese officials and experts, and American administrators at the American Bureau for Medical Aid to China (ABMAC), a New York philanthropic organization that sought to establish a penicillin pilot plant in the United States for Chinese researchers, reveal the extent of the perceived and real difficulties in producing penicillin on a mass scale in China. I argue that discussions over an American pilot plant for Chinese penicillin manufacture, in which Americans sought to transfer technologies that the NEPB was already developing, did not only reflect the challenges that the calamitous environment of everyday wartime China posed for medical research. The negotiations also reflected the way in which ABMAC presented the difficulties of everyday life in wartime China as incompatible with, rather than simply inhospitable to, medical science. Such assumptions help explain why efforts to set up a pilot plant in the United States failed, even as efforts in China ultimately succeeded. After a discussion of early research into penicillin in China's wartime hinterland, the paper considers the proposal by ABMAC to establish a pilot plant and discussions of the technical difficulties of establishing such a plant and transferring it to China. I then discuss the successful development of small amounts of therapeutic penicillin by the NEPB in 1944 and the impact of this event on the ultimate decision to redirect support for the pilot project to the NEPB at the end of the war.

These materials, many of which are drawn from the ABMAC archives, recover an important narrative in the history of pharmaceuticals and chemotherapy in twentieth-century 
China. The introduction of penicillin rarely features as an important event in the long sweep of Chinese medical historiography. ${ }^{9}$ Although there is a rich tradition in the history of pharmacy in China, the bulk of this scholarship has investigated traditional Chinese drugs. Aside from the work of the business historian Sherman Cochran, it has generally not focused on the history of foreign pharmaceutical enterprises or Western pharmaceuticals like sulfa drugs or other antibiotics. Miriam Gross and Xiaoping Fang have both discussed the significance of Western drugs for rural medicine and public health in the PRC. ${ }^{10}$ The pre1949 history of antibiotics in China can therefore provide valuable insights into their later use in China. Indeed, Wang Gaopeng argues that mass media played a crucial role in the acceptance and eventual veneration of penicillin in China as a miracle drug and that discourses of penicillin became a site for broader assertions of power by both the Nationalist and Communist Parties. And Frank Dikötter, Lars Laamann, and Zhou Xun have observed that the advent of penicillin and other antibiotics provided a viable alternative to some of the medicinal functions of opium, changing the landscape of therapeutic possibility in China. ${ }^{11}$

This history also underscores the importance of the Second Sino-Japanese War as a catalyst for medical research in China. The history of wartime science and medicine in China has seen increasing attention from scholars like John Watt, Wayne Soon, and Nicole Barnes. ${ }^{12}$ Yet the role of wartime work in antibiotic and pharmaceutical development has yet to be explored in full, especially given claims that Tang Feifan and his colleagues at the NEPB laid the foundations for the rise of the Western pharmaceutical industry in China. As Robert Bud writes, "Their expertise was crucial to the subsequent building of a global industry."13 Bud

\footnotetext{
${ }^{9}$ For instance, it does not appear in a timeline of significant events in medical history in Zhen Zhiya, Zhongguo yixue shi, 560-571.

${ }^{10}$ Cochran, Chinese Medicine Men; Fang, Barefoot Doctors and Western Medicine; Gross, Farewell to the God of Plague.

${ }^{11}$ Wang Gaopeng, "Qingmeisu zai jindai Zhongguo," 1; Dikötter, Laamann, and Zhou, Narcotic Culture, 205, 208.

${ }^{12}$ Watt, Saving Lives; Soon, “Coming from Afar”; Barnes, Intimate Communities.

${ }^{13}$ Bud, Penicillin, 76.
} 
gives the fullest Anglophone account of Chinese production of penicillin in his recent history of the drug, noting the surprising success of NEPB efforts in highly unfavorable conditions. ${ }^{14}$ $\mathrm{Xu}$ Dingding and Niu Yahua have also written thorough accounts of Chinese penicillin production that stress the significance of the NEPB's work in the wartime interior. ${ }^{15}$ These accounts enrich others that emphasize the rapid expansion of penicillin production after the 1949 establishment of the People's Republic of China, again suggesting the value of considering the role of war with Japan in this history. ${ }^{16}$

The narrative of Chinese penicillin production also contributes to global histories of antibiotic development and use. Most histories of penicillin focus on the well-known story of Alexander Fleming's 1928 discovery and Howard Florey's development of the compound as an effective antibiotic agent, typically thought of as a key step in contributing to a golden age of biomedicine in the mid-twentieth century. Recent scholarship has challenged this belief. In the most comprehensive recent history, Robert Bud argues that the medical triumphs, and triumphalism, resulting from penicillin should be understood alongside darker narratives of irresponsible misuse and overprescription. ${ }^{17}$ Peter Neushul suggests that the crisis of the World War II was crucial to facilitating the development of penicillin as a modern wonder drug because of the alliance it brought between state and industry in North America. ${ }^{18}$ Nicolas Rasmussen notes, however, that much of the industrially and philanthropically funded apparatus commonly thought to characterize "big biology" was already in place in the United States by the outbreak of war there in 1941; it was the novelty of federal patronage that transformed American biomedical research during this time. ${ }^{19}$

\footnotetext{
${ }^{14}$ Bud, Penicillin, 81.

${ }^{15}$ Xu Dingding, "Kangri zhanzheng shiqi"; Niu Yahua, "20 shiji 40 niandai."

${ }^{16}$ For an example, see Zhongguo yiyao baokan xiehui and Zhongguo yiyao gongye yanjiu kaifa cujin hui, Xin

zhongguo yaopin jianguan yu fazhan jingdian huicui, 139-141.

${ }^{17}$ Bud, Penicillin, 2.

${ }^{18}$ Neushul, "Fighting Research."

${ }^{19}$ Rasmussen, “Of 'Small Men,' Big Science and Bigger Business,” 116-117, 121-125.
} 
Outside English and American ambits, Bud notes that news of penicillin spread rapidly around the world, even in the constrained and secretive environment of war. Moreover, despite its theoretical and technical novelty, penicillin manufacture quickly became a priority for national governments across Europe and in China, Japan, and (postindependence) India. ${ }^{20}$ The development and circulation of penicillin in Japan is particularly noteworthy. Julia Yongue describes the mass production of penicillin in Japan as an unusual case of technology transfer from the United States in which scientists and government officials, rather than pharmaceutical firms, played central roles, and in which the absence of patenting until the end of the American Occupation facilitated novel and often productive relationships between science, state, and industry. ${ }^{21}$ However, Victoria Lee argues that rather than technology transfer, we should understand the Japanese case as one of "domestication" in which indigenous knowledge from the wartime and prewar periods of Japanese empire, drawing upon established concepts of microbes as agents of transformation that produced abundance from scarcity, contributed crucially to biomedical development. ${ }^{22}$ Scholarship on Japan is instructive for the case of China; as Lee's piece suggests, the uneasy exchanges between Chinese and American actors over the penicillin pilot plant proposed by ABMAC complicate notions of straightforward technology transfer to the Republic of China that American consultants sought to execute.

\section{Kunming: The Context of Wartime Medical Research and Drug Production}

Although southwest China had heretofore been a borderland at the fringes of modern public health and medical intervention, during the war the region became the epicenter of health administration for unoccupied China. After the Japanese invasion and occupation of eastern China forced the Republic of China's central administration to move from Nanjing to

\footnotetext{
${ }^{20}$ Bud, Penicillin, 75-82.

${ }^{21}$ Yongue, "Introduction of American Mass Production Technology," 213.

${ }^{22}$ Lee, "Microbial Transformations," 441-442.
} 
Chongqing, a number of government officials, professionals, and intellectuals migrated with it to China's western interior in 1938. Among the central government organizations that moved were the National Health Administration, which established its provisional headquarters in Geleshan outside Chongqing, and the NEPB, which reestablished its laboratories in Kunming, the capital of Yunnan Province.

The NEPB was the official manufacturer of vaccines, sera, and other "biological products" for the Republic of China. Founded in 1919 in response to a local outbreak of the plague in north China, its work quickly grew over the next years to include biomedical research on communicable diseases, epidemiological data collection, and the development of vaccination campaigns. ${ }^{23}$ During the 1920s and 1930s, the NEPB expanded its remit and capacities, adding a new branch and moving its headquarters to Nanjing in 1935. By this point, it had become a central entity in efforts to control and eradicate communicable diseases in China, and its offices manufactured over 40 different types of sera, vaccines, and antitoxins against human and animal diseases. ${ }^{24}$ When Tang Feifan assumed directorship of the bureau in 1938, he was in flight from Shanghai, where he had served as head of the Department of Bacteriology at the Henry Lester Institute of Medical Research and taught at the medical college at the prestigious National Central University (Guoli zhongyang daxue). ${ }^{25}$

Although the NEPB had left behind its relatively grand, well-equipped offices in Beijing, Nanjing, and Shanghai-the original Beijing bureau of the branch had been housed at the Temple of Heaven - in Kunming it continued its work of manufacturing biomedical materials and retained a number of highly trained specialists in its employ. Between 1937 and 1945, the NEPB produced millions of doses of vaccines against smallpox, cholera, and

\footnotetext{
${ }^{23}$ Yip, Health and National Reconstruction, 16.

${ }^{24}$ Chen, "Public Health in National Reconstruction," 60-68.

${ }^{25}$ Cheng, Ming, and Gao, "Recollection;" Wu Anran and Xie Xiaowen, "In Memory of Professor Tang Fei-fan," 512. Although National Central University was based in Nanjing, its medical school was sited in Shanghai during the 1930 s.
} 
typhoid fever. ${ }^{26}$ The Kunming headquarters oversaw branch laboratories and offices at Guiyang and Lanzhou. Because the capital of Yunnan was a site of major American and Allied activity as the eastern terminus of the Burma Road, it was relatively well connected to communications networks. The staff of the NEPB was therefore well placed to receive the news of penicillin's successful therapeutic development in the West.

Every week, Tang Feifan ran what modern biomedical laboratories call a journal club: a meeting to discuss new publications in foreign scholarly journals. In the autumn of 1941, Wei Xi, a bacteriologist and senior specialist at the NEPB, reported to this club on an August Lancet article by scientists at Oxford including Howard Florey and Ernst Chain on the extraction, purification, and assay of penicillin as an antibiotic drug. ${ }^{27}$ The NEPB staff was inspired by the news of penicillin's successful therapeutic use and especially the suggestion by the Lancet paper's authors that it would help the Allied war effort. ${ }^{28}$ The Chinese researchers henceforth begin using their spare time to investigate the southwestern environment — considering everything from old shoes and clothing to antique coins and local melons ${ }^{29}$ - to see if molds suitable for cultivating Penicillum notatum could be identified. The keen interest of NEPB staffers was not at all an isolated phenomenon, but rather part of what Wang Gaopeng describes as a "fanatical worship" (kuangre chongbai) of penicillin reflected by enthusiastic discussion in Chinese medical discourses and mass media in 1944 and 1945. Prominent intellectuals like Tao Xingzhi discussed penicillin as a political metaphor for good governance in calls for reform of the Nationalist state. It also became a fashionable term in broader popular culture, and the use of penicillin as a miraculous new panacea became a plot

\footnotetext{
${ }^{26}$ See also Brazelton, Mass Vaccination.

${ }^{27}$ Xu Dingding, "Experimental Production of Penicillin," 323; Bud, Penicillin, 79-81; Xu Dingding, "Kangri zhanzheng shiqi," 349; Abraham et al., "Further Observations on Penicillin."

${ }^{28}$ Xu Dingding, "Kangri zhanzheng shiqi," 349; for a firsthand account, see Tang Feifan, "Wu guo zi zhi qingmeisu."

${ }^{29}$ Tang Feifan, "Wu guo zi zhi qingmeisu," as quoted in Xu Dingding, "Kangri zhanzheng shiqi," 350.
} 
point in literary and cultural productions ranging from farces to short stories. ${ }^{30}$

Amid this public enthusiasm, NEPB's search for a suitable mold took years, until the spring of 1944. During this time, Tang Feifan and his colleague Huang Youwei traveled to India with support from the Rockefeller Foundation to survey public health organizations there; they returned to China with 10 strains of penicillin that had been isolated in England and America. Furthermore, a Chinese microbiologist returning from the University of Wisconsin, Fan Qingsheng, brought an additional three strains. The NEPB also obtained strains of penicillin from the United States Northern Regional Research Laboratory in Peoria, Illinois, where researchers had developed "deep" fermentation methods to culture penicillin within, rather than atop the surface of, a liquid medium. Yet both strains from this source performed poorly in attempts to culture penicillin; Tang and his colleagues suspected one of "dissociation with resultant loss of potency," perhaps as a result of the long journey from Peoria to Kunming. ${ }^{31}$ Despite this surfeit of strains with which to experiment, it was still not easy to identify molds with antibiotic properties — but eventually one was found. ${ }^{32}$ Contemporary narratives do not agree on the source of the mold that became the basis for penicillin production in China. Xu suggests that Lu Jinhan isolated it from meat broth, while Niu claims a mold on a broom yielded 11 strains with antibacterial properties. ${ }^{33}$ But once the NEPB had identified and isolated strains of mold that exhibited antibacterial properties, whatever the source, its staff sought means of cultivating and purifying the strains.

Meanwhile, the first industrially produced penicillin reached Chinese hospital beds. After the Lend-Lease Act permitted the transfer of 465 ampoules of penicillin from the United States to China, China's National Health Administration established a Central

\footnotetext{
${ }^{30}$ Wang Gaopeng, "Qingmeisu zai jindai Zhongguo," 19, 39-42. For an overview of the explosion of Chinese medical literature on penicillin at this time, see Zhang Changshao, Qingmeisu yu lianmeisu.

${ }^{31} \mathrm{Chu}$, Wong, Fan, and Tang, "Experimental Production of Penicillin," 91.

${ }^{32} \mathrm{Chu}$, Wong, Fan, and Tang, "Experimental Production of Penicillin," 90. The local molds were gathered over fourteen months from May 1944 to July 1945 and included such sources as orange peels, shoes, and cheese.

${ }^{33}$ Xu Dingding, "Kangri zhanzheng shiqi," 350; Niu Yahua, "20 shiji 40 niandai," 185.
} 
Penicillin Control Committee in the wartime capital of Chongqing to provide guidance for the drug's administration, establish cold storage facilities, and distribute penicillin to designated sites. $^{34}$ The first clinical uses of the drug were extremely positive. A report of 33 patients treated with penicillin in the Chongqing Central Hospital between August and November suggested that 19 men and women of a wide range of ages showed partial or clear improvement. A report of the committee summarized, "All the cases of pneumonia, chronic osteomyelitis, and acute infections due to staphylococci have responded remarkably well to treatment." The group planned to expand distribution to other cities in the unoccupied interior and estimated that China would need six hundred million Oxford units of the drug for the year 1945 (the initial shipment of 465 ampoules had contained 46.5 million units). ${ }^{35}$ Given just a taste of the abilities of penicillin, Chinese health administrators hungered for a fuller supply.

\section{New York: ABMAC Proposes a Penicillin Plant}

Throughout the fateful summer of 1944, these events had transpired at the edges of the Western world, through Sino-Indian relationships and local research efforts. Yet another group, ABMAC, was seeking the same result-penicillin production on a large scale in China — through radically different means. As John Watt has shown, ABMAC played a crucial role in the provision of wartime medical services to the Nationalist regime. ${ }^{36}$ Founded in October 1937 by overseas Chinese and Americans in New York, the organization funded many projects across wartime Nationalist territory. Over the course of the war, it sent a total of $\$ 9.5$ million to China, in a powerful projection of Chinese-American wealth and political

\footnotetext{
${ }^{34}$ Preliminary Report of the Central Penicillin Control Committee with Special Reference to the Activities of the Subcommittee for Civilians, January 25, 1945, p. 1, Archives of the American Bureau for Medical Aid to China, box 24 .

${ }^{35}$ Preliminary Report of the Central Penicillin Control Committee with Special Reference to the Activities of the Subcommittee for Civilians, p. 2, and Table II, The Hospital Number, Age, Sex, Clinical Diagnosis, Laboratory Findings, Dosage and Therapeutic Effects of Penicillin of 33 Cases in the Chungking Central Hospital Covering from August to November 1944, January 25, 1945, Archives of the American Bureau for Medical Aid to China, box 24 .

${ }^{36}$ Watt, Saving Lives.
} 
power. A key Chinese health administrator heavily involved in ABMAC was Lin Kesheng (Robert Lim), the prominent—and polarizing — general who advocated and fundraised for Chinese military medicine. ${ }^{37}$

Nicole Barnes notes that a widespread faith in the ability of modern Western scientific medicine to save lives suffused the spirit of donations to Chinese medical aid programs during the war. ${ }^{38}$ The activities of ABMAC thoroughly manifested such a spirit, as it worked with the National Health Administration and the Chinese Red Cross to allocate funds for the purchase of medical supplies and equipment. ABMAC also sponsored projects to purchase and send textbooks, journals, and anatomical and pathological microscope slides from the United States to medical schools in the wartime southwest, as well as postgraduate fellowship training for Chinese candidates at American medical schools. In 1943, the organization also established the first Chinese blood bank in Kunming. Wayne Soon has drawn attention to the significance of ABMAC in funding and establishing this project and the ways in which cultural understandings, nationalism, altruism, and economic crisis all contributed to the social meanings of blood that shaped the bank's activities. ${ }^{39}$

It was after the blood bank's establishment, in the spring of 1944, that ABMAC staffers first contemplated the development of a penicillin production plant in China. The notes of a meeting in New York on the afternoon of March 6, 1944, chaired by Liu Ruiheng (J. Heng Liu), previously vice-minister of health and now medical director of the US-based China Defence Supplies Commission, ${ }^{40}$ revealed ambitious desires. Unable to purchase penicillin directly for distribution in China, the group decided to focus on making it possible for Chinese microbiologists to produce the drug themselves. They would accomplish this by first establishing a small pilot plant in New York jointly with Indusco, the American

\footnotetext{
${ }^{37}$ Watt, Saving Lives, 123-158; Soon, "Coming from Afar."

${ }^{38}$ Barnes, Intimate Communities, 128.

${ }^{39}$ Soon, "Blood, Soy Milk, and Vitality," 427.

40 "Death of Dr. Liu," 2.
} 
Committee in Aid of Chinese Industrial Cooperatives. ${ }^{41}$ The goal was explicit technology transfer: to develop methods of producing crude and refined penicillin that "would, as far as possible, use only materials and equipment available in China." The minutes of the meeting further stipulated, "The method decided upon might not be the most efficient method for America, but it would be the best for China because of availability of materials and equipment. ${ }^{, 42}$ Norman Applezweig, a chemist and Indusco consultant involved in the project, reinforced visions of the project as a simple problem of technology transfer: "How can we transpose the highly mechanized American industrial practice into simple and more primitive conditions under which this industry must function in China?"43

Early plans for the pilot plant were unclear in most details, except one: a young Johns Hopkins-trained bacteriologist from China named Tong Cun would be trained in methods of penicillin production in order to lead the plant's transfer to China. Tong had been born into a Manchu family of officials who had served in the education administration of the Qing Dynasty. After receiving degrees from Yenching University and Peking Union Medical College, Tong had traveled to the United States, where in 1941, he received a doctorate of science from Johns Hopkins and became an instructor in bacteriology. ${ }^{44}$ The plan that ABMAC staffers developed in March 1944 was for Tong to "experiment on methods of producing penicillin until one was found which would be practicable in China and then ship the pilot plant to China as soon as possible" to supply the Chinese army with the drug. ${ }^{45}$ Tong himself would also return to China to supervise the operation of the plant, the training of

\footnotetext{
${ }^{41}$ Report on the Meeting of the ABMAC Penicillin for China Committee, September 22, 1944, Archives of the American Bureau for Medical Aid to China, box 24. The industrial cooperative movement in China began in 1938 as the work of H.H. Kung, minister of finance, and the New Zealander Rewi Alley. Pruitt, "Six Years of Indusco," 48.

${ }^{42}$ Minutes of Conference on the Production of Penicillin, March 6, 1944, Archives of the American Bureau for Medical Aid to China, box 24.

${ }^{43}$ Speech Given at ABMAC Annual Board of Directors Meeting by Norman Appelzweig, May 16, 1944, p.1, Archives of the American Bureau for Medical Aid to China, box 24.

${ }^{44}$ Jin Xinghua, Gongheguo shaoshu minzu kexuejia chuan, 71-72.

${ }^{45}$ Report on the Meeting of the ABMAC Penicillin for China Committee, September 22, 1944, Archives of the American Bureau for Medical Aid to China, box 24.
} 
personnel, and the establishment of new production laboratories in cities across unoccupied territory. ABMAC representatives originally planned to request funds from the Christian missionary organization United China Relief for this project. ${ }^{46}$

Plans for the mobile laboratory reflected American ideals of technology transfer as a medium for foreign diplomacy, as well as an opportunity to publicize (and possibly monetize) American scientific achievements. At the annual Board of Directors Meeting of ABMAC on May 16, Applezweig gave a speech to stakeholders unveiling the plans for the penicillin plant. He stressed the guidance ABMAC had received from government and commercial entities, stating somewhat hyperbolically that "the mere mention of the magic word China has opened to us the hearts and the minds of American research scientists and technical experts." He suggested that the pilot plant was more than a means of getting drugs to China. "We are sending to China not only a method for producing penicillin to meet its dire health needs," Applezweig proclaimed. "We believe we are sending to China a technique for research on and production of anti-biotic substances of which penicillin is only the first link in the chain." He concluded: "In addition to its anti-biotic properties, penicillin will act as a strong cement to permanently bind the friendship which the Chinese and American people feel for each other." ${ }^{47}$ The goal of political alliance was explicit; less so was the way in which Applezweig's vision of the relationship assumed total Chinese dependency on American ingenuity and benevolence.

\section{New York: The Technical Challenges of Technology Transfer}

Despite the hyperbolic language employed by Applezweig and others, the American model of pharmaceutical production that was going to do so much for the Chinese people was

\footnotetext{
${ }^{46}$ Report on the Meeting of the ABMAC Penicillin for China Committee, September 22, 1944, Archives of the American Bureau for Medical Aid to China, box 24.

${ }^{47}$ Speech Given at ABMAC Annual Board of Directors Meeting by Norman Applezweig, May 16, 1944, pp. 14, Archives of the American Bureau for Medical Aid to China, box 24.
} 
not yet stable. The science and technology of penicillin manufacture was changing so much, and so quickly, that it was extremely unclear what a pilot plant would entail. In June 1944, a joint meeting of ABMAC and Indusco representatives concluded that "because of the rapidly changing picture in the production of penicillin...the Committee recommends that no definite commitments as to the rental of a laboratory or further purchase of supplies for the pilot plant be undertaken until a report has been made by the Penicillin for China Committee on the scientific aspects. ${ }^{, 48}$ Another meeting later in the same month specified the technical problems anticipated for any large-scale penicillin plant in China, but failed to offer any productive solutions.

Much depended upon the technique of production chosen. As a mold, penicillin was not produced through chemical synthesis, the typical model for industrial pharmaceutical production at the time, but rather through methods of fermentation that sped the growth of fungal cultures. The drug could be manufactured through one of two methods: the bottle, or the tank. In the former method, originally developed in Oxford, the penicillin mold grew on the surface of a liquid broth, contained in bottles laid on their side to provide the maximum surface area possible for replication of the mold. Research at Northern Regional Research Laboratory in Peoria, Illinois found that deep-tank fermentation methods, in which penicillin was introduced with oxygen to large vats containing a nutrient broth, greatly increased production rates.

Which method should be used in China: the bottle or the vat? The concern for ABMAC and the Indusco staff was that in China, neither of these methods seemed viable. The bottle method seemed slow and outdated, but the tank method required too much specialized equipment and complex upkeep. Both methods used chemicals that were readily available in the United States, but not in China: specifically lactose and corn steep liquor.

\footnotetext{
${ }^{48}$ Conference on Penicillin: ABMAC and Indusco Representatives, Tuesday, June 13, 1944, 6:00 pm,” Archives of the American Bureau for Medical Aid to China, box 24.
} 
Lactose was the major carbon source for penicillin production but was not available in China and would need to be replaced by more readily available starches that had been dextrinized, or broken down into constituent sugars. ${ }^{49}$ Corn steep liquor, a by-product of corn wet milling and key additive to penicillin growth cultures, was another issue. "The discovery that corn steep liquor added to culture medium increases penicillin yield by many times forms the milestone upon which is built the penicillin production industry in its present scale," explained Tang Feifan and colleagues at the NEPB in 1945. "Corn steep liquor is a product of the starch fermentation industry and is not available as such in China." What had made sense for a laboratory in the corn country of Peoria, Illinois, was not going to work in Kunming. ${ }^{50}$

All of these technical problems only pertained to the first phase of penicillin development. It was one thing to stimulate the growth of penicillin mold in vats and bottles, but quite another problem to extract a usable drug from the solution. Again, methods for extracting penicillin commonly used in the United States relied on chemical agents not available in China, notably organic solvents and activated charcoal. "The extracting reagents, either organic solvent or charcoal, should be solved before we talk about production," Tong told ABMAC. He proposed starting with the bottle method of production, noting that "we could reach quite a sizeable production in China. If we do not have the bottles, we could use crude porcelain vessels as well.",51

Tong's comment nodded to other anticipated problems and fundamental worries on the part of the American participants, which had to do with the basic conditions of wartime China. The question of maintaining sterile conditions - a specter that haunted every biological and chemical laboratory in wartime China — was a pressing one, as was the ability of any given institution to maintain consistent refrigeration of strains. The more general dearth of

\footnotetext{
${ }^{49}$ Minutes of the Meeting of the Special Advisory Committee on Penicillin for China Project of ABMAC and Indusco," June 23, 1944, Archives of the American Bureau for Medical Aid to China, box 24.

${ }^{50}$ Chu, Wong, Fan, and Tang, "Experimental Production of Penicillin," 92.

${ }^{51}$ Minutes of the Meeting of the Special Advisory Committee on Penicillin for China Project of ABMAC and Indusco, p. 3, June 23, 1944, Archives of the American Bureau for Military Aid to China, box 24.
} 
experts in Western medicine was a constant worry. The philanthropist and chemist Donald Othmer said at one point, "If you start in China with people who have not been trained here you are back to the 1929 method." 52 However, as Tong Cun pointed out in one New York meeting, "It will be difficult in China to get well trained personnel on penicillin. We do not have people here either." 53

The anticipation of problems related to the adaptation of penicillin production thus revealed a perceived gap between the United States and China, not only in terms of specific technical questions like the scarcity of activated charcoal in China, but also in terms of how the wartime environment shaped the possibilities of microbiology. The debate was fundamentally over the standard operating conditions of medical research in China, and the ways in which Americans assumed such conditions to be inadequate and antithetical to the mass production of penicillin.

Given these technical concerns, there was fundamental disagreement as to whether ABMAC's plan was the best way forward. "I have maintained from the beginning that it is very important to send certain special equipment and one or two experts to China as soon as possible," wrote Liu Ruiheng in a June 1944 memo. "There are advantages to setting up a complete test plant in New York and then to ship the whole outfit to China, but this will take too much time and there will be difficulties such as those facing the Blood Bank today." He recommended instead that Tang Feifan come to the United States from Kunming to study penicillin manufacture and purchase equipment that could make the NEPB a penicillin production center. ${ }^{54}$ Lin Kesheng also advocated for the redirection to the NEPB of the funding and supplies ABMAC had allocated for its own penicillin plant. He wrote, "If...we

\footnotetext{
${ }^{52}$ Minutes of the Meeting of the Special Advisory Committee on Penicillin for China Project of ABMAC and Indusco, p. 3, June 23, 1944, Archives of the American Bureau for Military Aid to China, box 24.

${ }^{53}$ Minutes of the Meeting of the Special Advisory Committee on Penicillin for China Project of ABMAC and Indusco, June 23, 1944, Archives of the American Bureau for Military Aid to China, box 24.

${ }^{54}$ Memorandum by J. Heng Liu, "Penicillin," June 22, 1944, Archives of the American Bureau for Medical Aid to China, box 24 .
} 
might get enough equipment, we might use the Epidemic Prevention Bureau and set up a real plant."55

Another setback emerged from efforts on the part of Indusco, the American group supporting Chinese industrial cooperatives, to seek the sponsorship of commercial partners and secure for Tong Cun research experience in an industrial laboratory. The question of industrial involvement in penicillin production was a loaded one. In the United States, pharmaceutical companies that had contracted with the federal government to produce penicillin during the war nevertheless anticipated that the drug as a proprietary product would be phenomenally lucrative after the end of conflict. "After the war penicillin will be a purely commercial product and the tricks of the trade will be kept secret," noted Donald Van Slyke, a preeminent chemist at the Rockefeller Institute for Medical Research and a cofounder of ABMAC, in a June 1944 meeting. ${ }^{56}$ Although Indusco sought aid from a pharmaceutical company to establish a pilot plant in the United States, with the incentive that the firm would have first rights to establish facilities in China after the war ended, its efforts were unsuccessful. ${ }^{57}$ A letter from Helen Stevens, the executive director of ABMAC, to K.K. Chen, director of pharmacological research at Eli Lilly's research laboratories, shed some light on this question. Stevens summarized a conversation they had had several days previously, in which Chen suggested that "no commercial plant would be willing to let Dr. Tung [Tong] in on their trade secrets; therefore, if Dr. Tung is to obtain practical experience it will have to be in a pilot plant." 58

\footnotetext{
${ }^{55}$ Minutes of the Meeting of the Special Advisory Committee on Penicillin for China Project of ABMAC and Indusco, held at the office of ABMAC," New York City, June 23, 1944, Archives of the American Bureau for Medical Aid to China, box 24.

56 "Minutes of the Meeting of the Special Advisory Committee on Penicillin for China Project of ABMAC and Indusco, held at the office of ABMAC," New York City, June 23, 1944, Archives of the American Bureau of Medical Aid to China, box 24.

${ }^{57}$ Report on the Meeting of the ABMAC Penicillin for China Committee, September 22, 1944, Archives of the American Bureau for Medical Aid to China, box 24.

${ }^{58}$ Helen Stevens, New York, to K.K. Chen, Indianapolis, September 19, 1944, Archives of the American Bureau for Medical Aid to China, box 24.
} 
By midsummer, ABMAC members deemed it necessary to consult higher authorities. On July 13, 1944, Donald Van Slyke, Lin Kesheng, and Liu Ruiheng, all representing ABMAC, met with Frederick J. Stock, of the Office of Production Management in the United States War Production Board, and Dr. Chester Keefer, chairman of the National Research Council's Committee on Chemotherapy (responsible for rationing penicillin supplies for civilian use) in Washington, DC. The representatives from ABMAC asked the American officials how practical it would be to establish a plant under the direction of Tong Cun to produce penicillin in China. The response was encouraging; Stock and Keefer suggested that the project establish a small laboratory that could be set up within three months and produce one hundred million Oxford units of penicillin per month, using the bottle method of production. ${ }^{59}$ They recommended that the site should be one, in the words of Lin Kesheng, "where we could work day and night, and where we could have complete freedom." A few days later, on the evening of July 19, ABMAC held its own meeting at its offices on Broadway. Two bacteriologists, Robert Coghill (who had directed penicillin research at the North Regional Research Laboratory in Peoria) and his colleague George Ward, had been specially invited to discuss the technical problems of a pilot plant.

In the course of the discussion, a consistent theme that emerged was the question of what exactly would be the most useful means of getting penicillin to China. Embedded in the conversation were, again, assumptions about what was "normal” in China versus America. The discussion seems to have been precipitated by the news that a donor had given one million dollars to United China Relief for the purchase of drugs to supplement what the Chinese government could buy through the Lend-Lease program. Van Slyke observed, "It appears to be the consensus of opinion that it is desirable...to get as much penicillin to China

\footnotetext{
${ }^{59}$ Report of the Penicillin for China Project, Executive Committee Meeting, July 25, 1944, Archives of the American Bureau for Medical Aid to China, box 24.
} 
as possible as soon as possible. ${ }^{60}$ The meeting notes recorded the purpose of the penicillin purchases that the Chinese government was making through this agreement from the War Production Board: "The supply of penicillin would be just sufficient to give experience to doctors in China but would not take care of sufficient number of cases to have any great effect on the army casualties." ${ }^{61}$ The message was clear: this pilot project was not going to affect the everyday lives of soldiers or civilians in wartime China. Left unspoken, however, was the possibility that it might shape the course of the war to come between the Nationalist Party and the Communist Party.

Not everyone agreed with this course of action. Liu Ruiheng protested the small amounts of penicillin being sent to China, saying, "Treating 50 cases a month does not mean anything at all." Van Slyke responded, "The denying of penicillin to China, just because she does not know how to use it is just like telling your daughter to stay away from the water until she knows how to swim.” Coghill responded, “[Frederick] Stock is extremely sympathetic. If you can get by political interference amount available will increase very fast, as I know production will increase rapidly." And George Ward pointed out to the Chinese participants that "learning bottle method will never teach you how to run a tank plant." There was also further discussion of the technical nuts and bolts: Did China have sufficiently reliable infrastructures of electric power? How could activated charcoal be produced there? Could wood distillate provide sufficient materials for amyl acetate, and could soybean extract replace steep liquor? When the meeting adjourned at 10:30 pm, these questions remained largely theoretical, but they had the cumulative effect of suggesting that the problems of transferring penicillin production technology to China were prohibitively manifold. ${ }^{62}$

\footnotetext{
${ }^{60}$ Minutes of the Meeting of the Special Advisory Committee on Penicillin for China Project of ABMAC and Indusco, July 19, 1944, p. 4, Archives of the American Bureau for Medical Aid to China, box 24.

${ }^{61}$ Minutes of the Meeting of the Special Advisory Committee on Penicillin for China Project of ABMAC and Indusco, July 19, 1944, p. 2, Archives of the American Bureau for Medical Aid to China, box 24.

${ }^{62}$ Minutes of the Meeting of the Special Advisory Committee on Penicillin for China Project of ABMAC and Indusco," July 19, 1944, p. 4, Archives of the American Bureau for Medical Aid to China, box 24.
} 
Kunming: The Cultivation of Penicillin at the NEPB

In the summer of 1944, senior specialists at the NEPB had identified strains of mold that demonstrated antibacterial properties, but struggled to cultivate them, much less extract a viable pharmaceutical compound. The team dedicated to this work was led by Tang Feifan but included senior specialists Huang Youwei and Zhu Jiming, the latter of whom worked especially intensively on the project. Fan Qingsheng, an American-trained bacteriologist at the blood bank ABMAC had founded in Kunming, quickly became involved as well. At the same time, Tang was corresponding frequently with Tong Cun in the United States. ${ }^{63}$

As ABMAC discussions had indicated, a major problem for the cultivation of penicillin in China was the unavailibility of corn steep liquor, the crucial additive for culture mediums. The NEPB staffers who faced this problem had to come up with practical alternatives. They used a combination of cane sugar, available locally, and a liquor they distilled from corn specially for penicillin production. ${ }^{64}$ After incubation of the flasks containing the growth preparation, the researchers extracted the penicillin using methods that Tong Cun had discussed with ABMAC. The fundamental problem had been the limited availability of organic solvents and activated charcoal. Tang's team used amyl acetate to extract penicillin into aquaeous solution, employing a filter of sand and silk layers to separate the solvents. The NEPB then added charcoal obtained from a local sugar refinery supplier to the solution; further filtration, drying, and other chemical methods produced a concentrated solution that could be used therapeutically. ${ }^{65}$

On September 5, the NEPB produced 5 ampoules of penicillin, each containing five thousand Oxford units. Two were sent to the wartime capital at Chongqing and one each went

\footnotetext{
${ }^{63}$ Niu Yahua, "20 shiji 40 niandai," 186.

${ }^{64}$ Chu, Wong, Fan, and Tang, "Experimental Production of Penicillin," 92.

${ }^{65}$ Chu, Wong, Fan, and Tang, "Experimental Production of Penicillin," 96-97.
} 
to Norman Heatley at Oxford and to the University of Wisconsin, Madison; the NEPB kept the final bottle for itself. ${ }^{66}$ Assays at Oxford and the University of Wisconsin confirmed that the Chinese production contained 177 Oxford units of penicillin per milligram. ${ }^{67}$ The second batch of penicillin that the NEPB produced was sent first to the local Huidian Hospital (Huidian yiyuan), where physician Yao Hanping used it to treat a selection of patients and saw remarkable improvement in otherwise hopeless cases, and later to the Kunhua Hospital (Kunhua yiyuan). ${ }^{68}$

The article that Tang Feifan and his colleagues published in 1945 announcing their achievement was the cover story of that month's Chinese Medical Journal. In the piece, they described the challenges they had faced in the course of experimental production, attributing most of them to the poor facilities and lack of available equipment in the wartime interior. For instance, it was easier to send assays abroad than to try to perform them in China. "It is often difficult to obtain glass or porcelain cylinders of well beveled end to permit a satisfactory seal" in attempting the standard Oxford method, explained the 1945 paper's authors, who then went on to describe a method they had developed to perform the assay using a cork borer to place holes on the seeded agar. ${ }^{69}$ The team completed clinical trials, but in its initial report cautioned that "the dosages are entirely arbitrary and in general the total amount given is far too small to permit any clinical judgement"; instead, their trials simply proved that the penicillin the NEPB had developed could be used therapeutically. ${ }^{70}$

ABMAC heard the news more or less as it happened because Fan Qingsheng, the bacteriologist for the blood bank that ABMAC ran in Kunming, quickly became involved in the penicillin project. "Two weeks after my arrival at Kunming, I moved down to the West Hill and started work on culture of the mold and the extraction of penicillin with Dr. Tang and

\footnotetext{
${ }^{66}$ Niu Yahua, "20 shiji 40 niandai," 185.

${ }^{67}$ Chu, Wong, Fan, and Tang, "Experimental Production of Penicillin," 97.

${ }^{68}$ Niu Yahua, "20 shiji 40 niandai," 186.

${ }^{69}$ Chu, Wong, Fan, and Tang, "Experimental Production of Penicillin," 98.

${ }^{70}$ Chu, Wong, Fan, and Tang, "Experimental Production of Penicillin," 100.
} 
his staff," explained Fan in a report that he sent to ABMAC on September 4. The report characterized the work as a "joint project" of the NEPB and the blood bank and described its equipment, experimental results, and current production levels. A brief summary of the patients cured with penicillin in the first experimental trials gives a sense of the kinds of medical problems that merited treatment, many of which had nothing to do with war at all: "large carbuncle on back," "staphylococcus infected dog-bite wound," "fistula following empyema as complication of pneumonia.",71

The news that the NEPB had managed to produce viable penicillin complicated the ambitions of ABMAC. At 5:30 pm on September 22, 1944, the Penicillin for China Committee met at the ABMAC offices on Broadway in New York. The news was disheartening. Negotiations between Indusco and a commercial partner had failed, and recent experiences of the blood bank in Kunming had suggested that "it is not at all practical to send a trained team and American made equipment to China." The fact that Tang Feifan had already begun producing small quantities of penicillin domestically made it all the more absurd to contemplate such a project. ${ }^{72}$ The success of domestic production in wartime circumstances made it rather strange that such a complex, expensive project of technology transfer from America should founder. Even as the committee was deciding on the impossibility of the transfer, it was happening. Wartime conditions of scarcity and substitution, which had presented fearsome obstacles to American technology transfer, had nonetheless provided the means for Chinese manufacture of the drug.

From New York to Kunming and Kunming to Beijing: Repatriations amid Civil War

\footnotetext{
${ }^{71}$ Report by C.S. Fan [Fan Qingsheng], “On Penicillin Work,” September 4, 1944, Archives of the American Bureau for Medical Aid to China, box 24.

${ }^{72}$ Report on Penicillin Meeting, September 22, 1944. Archives of the American Bureau for Medical Aid to China, box 24.
} 
Given the developments in Kunming, it was now very unclear how the transfer of a separate penicillin plant from the United States to China, while useful, would effect radical transformation of the kind Applezweig and others had originally envisioned. At the September 1944 meeting, committee members concluded that "a pilot plant is no longer feasible" and that it should "support Dr. F.F. Tang, who is producing penicillin in China, by buying equipment for him and sending Dr. Tsun Tung [Tong Cun] back to China as soon as possible to help in the production of penicillin there." ABMAC would also purchase as much penicillin as possible to send to China. ${ }^{73}$ On January 13, 1947, Tang acknowledged receipt, on behalf of the NEPB, of $\$ 18,745,000$ (in Chinese currency) from ABMAC in support of the penicillin plant. ${ }^{74}$

On October 1, 1944, Tong — who was being repatriated despite stating 10 days previously that he felt he lacked the training to successfully return and launch penicillin production in his native country-wrote an impassioned letter to ABMAC's executive director, Helen Stevens. It suggested Tong's fear that Chinese colleagues would think poorly of him for not doing more to effect penicillin production in China: "I do mind," he wrote, "that people in China will blame me if I cannot do anything more than they can do now." $\mathrm{He}$ emphasized his dedication to ABMAC and stressed the need for Chinese researchers to travel to the United States to learn more about the drug's manufacture there. "I am afraid that while we have painstakingly paved the way for the making of penicillin for China," he wrote darkly, "we might not have the opportunity to use it to any extent."75

By the end of the month, Tong's spirits appeared to have lifted. In a second letter to Stevens, he sent a plan of action to prepare for his return to China. Before sailing across the

\footnotetext{
${ }^{73}$ Report on Penicillin Meeting, September 22, 1944. Archives of the American Bureau for Medical Aid to China, box 24.

${ }^{74}$ F.F. Tang, Beijing, to ABMAC offices, New York, January 13, 1947, Archives of the American Bureau for Medical Aid to China, box 9.

${ }^{75}$ Tsun Tung to Helen Stevens, October 1, 1944, Archives of the American Bureau for Medical Aid to China, box 24. I have used the older romanization of Tong Cun's name here because that is the name by which he was known at ABMAC.
} 
Pacific, he would spend two weeks at Penn State to study the means of extracting penicillin from culture, then a month at the Peoria Laboratory to learn more about the tank method of penicillin cultivation. Finally, he would spend two weeks at the commercial laboratories of Eli Lilly and Squibb, having apparently found a way to access those industrial laboratories after all. ${ }^{76}$ "I expect that in the next one or two years every bacteriologist in China will become keenly interested in penicillin and a corresponding number of chemists will become familiar with the making of penicillin," he wrote, before going on to request some equipment to take with him back to China. In addition to glassware and lactose, Tong asked for $\$ 2,000$ to be set aside for the manufacture of "miniature tanks and accessories," which he apparently intended to use as teaching tools. ${ }^{77}$ On July 7,1945 , Tong made a further plea for material and financial support for penicillin production even though the war was drawing to a close, based on the project's lasting significance. "We in China shall stand by this work, war or peace," he asserted. ${ }^{78}$

The end of World War II did not augur peace for China, soon beset by civil war between the Communist Party and the Nationalist Party. Nevertheless, shortly after the Japanese surrender, the National Health Administration and other state medical institutions made triumphant returns to eastern China's formerly occupied urban centres. The NEPB, too, reestablished its offices in Beijing and Nanjing. Penicillin production, supported by ABMAC, was by now a fundamental part of its work, and Tang ensured the establishment of an antibiotic research laboratory within its Beijing headquarters as they were rebuilt after the war; Tong Cun assumed leadership of this office upon his return from the United States. ${ }^{79}$ Tang reported in December 1948 that monthly yields since August of that year had doubled

\footnotetext{
${ }^{76}$ Tsun Tung to Helen Stevens, October 30, 1944, Archives of the American Bureau for Medical Aid to China, box 24 .

${ }^{77}$ Tsun Tung to Helen Stevens, October 30, 1944, Archives of the American Bureau for Medical Aid to China, box 24.

${ }^{78}$ Tsun Tung, Galveston, Texas, to Frank Meleney, New York, July 7, 1945, Archives of the American Bureau for Medical Aid to China, box 24.

${ }^{79} \mathrm{Xu}$, "Kangri zhanzheng shiqi," 357.
} 
using chemical methods and then stood at about 1,500 bottles, each containing two hundred thousand units of penicillin. From August 1948, the NEPB had doubled this figure using chemical methods. The NEPB had switched from a bottle method to the vat, using four 30 gallon cultivation tanks; Tang hoped to acquire two 300-gallon tanks in order to expand production more rapidly, but noted that efforts to have this equipment made locally had failed. ${ }^{80}$

Tang wrote to ABMAC member Frank Meleney in March 1946, shortly after the NEPB had returned to its facilities in Beijing. "The National Government has given us a special grant to build a penicillin laboratory to house the equipment which you have so kindly bought for us," he explained, and asked Meleney to purchase some additional equipment, including a centrifuge and electronic microscope. He hinted that the latter might not be solely for the purpose of producing penicillin, saying, "I have been interested in the study of filterable viruses for many years and I would like to have an Electronic microscope for further work on the subject." ${ }^{, 81}$ This request suggested that Tang was trying to make the fullest use of a resource that he knew might not last much longer — after all, the end of war with Japan had removed the primary justification for the existence of ABMAC, even if civil war was only just beginning (again).

ABMAC did not close its operations, but did refocus them on a program offering fellowships to faculty at national medical schools in China. Meanwhile, other organizations emerged to facilitate penicillin production. The most significant of these was a postwar initiative by the United Nations Relief and Rehabilitation Agency (UNRRA) to provide expertise and equipment in the manufacture of penicillin to war-torn nations. The project

\footnotetext{
${ }^{80}$ Tang Feifan, The Present Status of the NEPB Penicillin Laboratory, December 1948, Archives of the American Bureau of Medical Aid to China, box 24, 2.

${ }^{81}$ Tang Feifan, Beijing, to Frank Meleney, New York, March 14, 1946, Archives of the American Bureau for Medical Aid to China, box 24.
} 
focused on Eastern Europe, but indirectly extended as far as China. ${ }^{82}$ In China, the Chinese National Relief and Rehabilitation Administration (Xingzheng yuan shanhou jiuji shu) was established to distribute aid from UNRRA. In 1945, its Jiangxi Province branch received a small batch of penicillin that was sufficient to treat 79 patients, many of whom recovered fully.

Like others with access to the drug, the physician overseeing experimental treatment in Jiangxi presented these initial cases as materials of interest and significance in medical literature. ${ }^{83}$ Although Tang Feifan fretted over the quantity of penicillin he could produce at the NEPB in Beijing, researchers across China were excited to make use of this new therapeutic measure. They began publishing articles about their research using small amounts of penicillin in clinical contexts. Researchers focused on the ways in which penicillin might successfully treat pathologies especially common in China. They tried to use penicillin to treat lung abscesses, complications of kala-azar (the parasitic disease leishmaniasis), blood clots in sinus cavities, and Chinese louse-borne relapsing fever. ${ }^{84}$ They wrote of their experiences injecting penicillin directly into the spinal column. ${ }^{85}$ One physician went so far as to invent a machine for aerosolized penicillin distribution, suggesting in the Chinese Medical Journal that penicillin in such a form could serve as an effective means of treating lobar pneumonia and other pulmonary diseases. The author stressed that the apparatus could be made easily from materials at hand in most places in China, a significant advantage given that foreign nebulizers were unavailable "on account of the present political situation."

Yet as the final quote indicates, this excitement took place at a time of great change. Tang ended his December 1948 report to ABMAC with an ominous meditation on the future.

\footnotetext{
${ }^{82}$ Bud, Penicillin, 75-82.

${ }^{83}$ Ao, "Qingmeisu dui waike jibing," 4-12, as discussed and quoted in Wang, "Qingmeisu zai Zhongguo," $47-$ 52.

${ }^{84}$ Zhong et al., "Efficacy of Penicillin"; Niu and Liu, "Penicillin in the Treatment of Putrid Lung Abscess"; Cao, Chen, Chen, and Liao, "Treatment of Thrombophlebitis"; Lin, "Preliminary Study."

${ }^{85}$ Song, "Intrathecal Administration of Penicillin."

${ }^{86}$ Guo, "A Simple Apparatus for Penicillin Aerosolization," 504-505.
} 
Although the NEPB was functioning as usual in terms of its production, it had also become the site of a military hospital and was functionally besieged by several different groups of soldiers who "wanted to use the laboratory buildings for their purposes." 87 In a postwar environment of rapid social and political change, staffers left the NEPB, and China, in a steady stream. In September, Tong Cun took up a position supervising penicillin production in Shanghai, ${ }^{88}$ and Ma Yucheng flew to Toronto to take up a WHO fellowship for advanced training in antibiotics. Tang noted that two workers in the assay department "left the laboratory in September and October—both to get married." ${ }^{89}$ Although the turmoil of civil war was rapidly engulfing Beijing, the Ministry of Health instructed the NEPB not to move the penicillin plant, or any of its other offices, out of the city. ${ }^{90}$ Tang explained, "As there is safety and peace nowhere even had we the finances for any major removal, we have decided finally to let this laboratory - together with the other NEPB laboratories-remain at the Temple of Heaven and Heaven only knows what is in store there for the future."91

Tang Feifan, Tong Cun, and other researchers did stay in China after the 1949 establishment of the People's Republic of China, although the Nationalist regime they served did not. The NEPB was renamed the Beijing Vaccine and Serum Institute and continued to oversee the national production of a variety of biological products. The production of penicillin had likely helped consolidate the NEPB's authority over the production of biologicals of a therapeutic, as well as preventive, nature. Tang continued to work there, although resuming his prewar research on trachoma, an eye disease widespread in China during the Republican period. Tang is largely remembered worldwide as the first scientist to

\footnotetext{
${ }^{87}$ F.F. Tang, Shanghai, to J. Heng Liu, Shanghai, December 20, 1948, Archives of the American Bureau for Medical Aid to China, box 24.

${ }^{88}$ Jin Xinghua, Gongheguo shaoshu minzu kexuejia chuan, 73.

${ }^{89}$ Tang Feifan, The Present Status of the NEPB Penicillin Laboratory, December 1948, p. 1, Archives of the American Bureau for Medical Aid to China, box 24.

${ }^{90}$ J. Heng Liu, Shanghai, to Magnus Gregersen, New York, December 21, 1948, Archives of the American Bureau for Medical Aid to China, box 24.

${ }^{91}$ Tang Feifan, The Present Status of the NEPB Penicillin Laboratory, December 1948, p. 2, Archives of the American Bureau for Medical Aid to China, box 24.
} 
successfully identify the cause of trachoma in 1957, when he identified, isolated, and cultivated the bacterium Chlamydia trachomatis. ${ }^{92}$ He tragically passed away shortly thereafter. Fan Qingsheng, too, won acclaim as a specialist in agricultural microbiology, especially in promoting the cultivation of edible and medicinal mushrooms in China, and he enjoyed an illustrious teaching career in Nanjing. ${ }^{93}$ Despite his fear of being blamed for failing to complete an impossible task in transferring a pilot plant from the United States, Tong Cun is memorialized in contemporary accounts as having "established the foundation of the antibiotic enterprise" in China. After the establishment of the People's Republic, Tong worked in a variety of pharmaceutical manufacturing units in Shanghai, ultimately enjoying a long career at the intersection of academia and industry. ${ }^{94}$

\section{Conclusion}

It is easy, and tempting, to read the narrative of Tang Feifan and his colleagues at the NEPB as one of unqualified success: of a ragtag team of researchers in desperate conditions of war, relying on their wits and ingenuity to produce a lifesaving drug despite the naysaying of wealthy and powerful American colleagues. Yet to do so would unfairly overlook the extent of the efforts of ABMAC personnel and somewhat overstate the impact of the NEPB's work. The technologies, texts, and human resources necessary for penicillin manufacture traveled to China in many different forms, at many different times: through the Lend-Lease Act, through the long travels of Tong Cun, even in the shipment of the latest edition of the Lancet to a remote laboratory at the fringes of the Chinese polity. Yet the first successful production of the drug did happen in Kunming at the NEPB, and it did happen amid the wartime conditions of scarcity and calamity that had come to describe everyday life for

\footnotetext{
${ }^{92}$ Tang et al., "Studies on the Etiology of Trachoma."

${ }^{93}$ Xu Jianping, "The Life and Work of Dr. Fan Qingsheng," 554-556; Lou Wuji and Zhou Xiangquan, "Fan Qingsheng," 192.

${ }_{94}$ Jin Xinghua, Gongheguo shaoshu minzu kexuejia chuan, 71-75.
} 
millions of people in China's interior.

Amid technical debates over scientific possibility and efforts to find Chinese substitutes for American materials, the case files of the first patients in wartime China who were actually treated with penicillin stand out. This article has discussed some ramifications of the terms of everyday life in wartime China for a small and elite group of medical researchers, both as they experienced it and as American philanthropists perceived it, but the advent of penicillin promised to change the terms of everyday life for almost everyone in China. It made formerly fatal conditions like gonorrhea or hospital infections survivable. We do not have easy access to their perspectives in surviving records, but the range of patientsmale and female, young and old — who were the experimental subjects of the first therapeutic use of penicillin in China represent the first group of individuals who experienced this new version of what would quickly become normal medical practice.

Questions of the "normal" in biomedical research and development are more relevant than ever when it comes to the production of antibiotics. After the economic reforms of the 1980s that incentivized the sales of medicines by tying them to doctors' salary scales, physicians in China inadvertently systematically overprescribed penicillin and other antibacterial drugs. Global pharmaceutical firms' heavy promotion of antibiotics, as well as the widespread regular use of tetracycline and related drugs in fisheries and livestock management, contributed to the proliferation of antibiotic-resistant bacteria in the environment. Although recent reforms have made Chinese physicians' pay totally independent of their prescribing habits and prohibited over-the-counter sales of antibiotics, bacteria that are resistant to treatment with antibiotics remain a major public health threat, in China and around the world. ${ }^{95}$ The history of the development of penicillin in China provides

\footnotetext{
${ }^{95}$ Hvistendahl, “China Takes Aim,” 795.
} 
a timely reminder, then, of the fragility, difficulty, and historical contingency of their development.

\section{Notes on the Contributor}

Mary Augusta Brazelton is currently a university lecturer in global studies of science, technology, and medicine in the Department of History and Philosophy of Science at the University of Cambridge. She is also a research fellow of the Needham Research Institute. She received her PhD from Yale University and has taught previously at Tufts University. Her research primarily focuses on the history of science, technology, and medicine in modern China and East Asia, with allied interests in Manchu studies. Her book, Mass Vaccination: Citizens' Bodies and State Power in Modern China, will be published by Cornell University Press in October 2019.

\section{Glossary}

Ao Guohui 敖国辉

Chongqing 重庆

Fan Qingsheng 樊庆笙

Geleshan 歌乐山

Guiyang 贵阳

Guoli zhongyang daxue 国立中央大学

Huang Youwei 黃有为

Huidian yiyuan 惠滇医院

Jin Baoshan (also P.Z. King) 金宝善

kangjunsu 抗菌素

kangshengsu 抗生素

kuangre chongbai 狂热崇拜

Kunhua yiyuan 昆华医院

Kunming 昆明

Lanzhou 兰州

Lin Kesheng 林可胜

Lin Shujin 林淑瑾

Liu Ruiheng (also J. Heng Liu) 刘瑞恒

Lu Jinhan 卢锦汉

Ma Yucheng (also Y.C. Ma) 马誉澂

Tang Feifan 汤飞凡

Tao Xingzhi 陶行知

Tong Cun (also Tung Tsun) 童村

pannixilin 盘尼西林

qingmeisu 青霉素

Wang Gaopeng 王高朋

Weishengshu 卫生署 
Wei Xi 魏曦

Xingzheng yuan shanhou jiuji shu 行政院善后救济署 Yao Hanping 姚汉平

Zhu Jiming 朱既明 


\section{Bibliography}

Abraham, E.P., E. Chain, C.M. Fletcher, A.D. Gardner, N.G. Heatley, M.A. Jennings, and Florey, H.W. "Further Observations on Penicillin.” Lancet 238, no. 6155 (August 16, 1941): 177-189.

Ao Guohui 敖国辉. “Qingmeisu dui waike jibing zhi zhiliao baogao” 青霉素对外科疾病之 治疗报告 [Report on the Therapeutic Use of Penicillin in the Surgical Department]. Jiangxi sheng li yixue zhuanke xuexiao xiao kan 江西省立医学专科学校校刊 [Journal of the Medical School of the Jiangxi Province]. Supplement no. 11 (1948): 4-12. Quoted in Wang Gaopeng 王高朋. “Qingmeisu zai jindai Zhongguo de chuanbo yu jieshou” 青霉素在近代中国的传播与接受 [The Dissemination and Acceptance of Penicillin in Modern China]. MA diss., Hebei University, 2018, 47-51.

Archives of the American Bureau for Medical Aid to China. Columbia University Rare Books and Manuscripts Library, New York, NY.

Barnes, Nicole Elizabeth. Intimate Communities: Wartime Healthcare and the Birth of Modern China, 1937-1945. Oakland, CA: University of California Press, 2018.

Bello, David A. “To Go Where No Han Could Go for Long: Malaria and the Qing Construction of Ethnic Administrative Space in Frontier Yunnan.” Modern China 31, no. 3 (July 2005): 283-317.

Brazelton, Mary Augusta. Mass Vaccination: Citizens' Bodies and State Power in Modern China. Ithaca, NY: Cornell University Press, forthcoming 2019.

Bud, Robert. Penicillin: Triumph and Tragedy. Oxford: Oxford University Press, 2007.

Cao Xizhong (S.C. Tsao) 曹錫中, Chen Guisheng (K.S. Chen) 陳桂生, Chen Congmin (C.M. Chen) 陳聰敏, and Liao Dawei (D. Lyen) 廖大衛. “The Treatment of Thrombophlebitis of Cavernous Sinus with Penicillin.” Chinese Medical Journal 66, no. 12 (Dec. 1948): 692-693.

Chen, Lawrence M. (Chen Wentong). "Public Health in National Reconstruction." Information Bulletin: Council of International Affairs 3, no. 3 (Feb. 1937): 53-67. Cheng Guangsheng, Ming Li, and George F. Gao. "Recollection: 'A Friend to Man,' Dr. Feifang Tang; A Story of Causative Agent of Trachoma, from 'Tang's Virus' to Chlamydia Trachomatis, to 'Phylum Chlamydiae." Protein \& Cell 2, no. 5 (2011): $349-350$. 
Chu, C.M., Y.W. Wong, C.C. Fan, and F.F. Tang. "Experimental Production of Penicillin in China." Chinese Medical Journal 64, no. 5-6 (Sept.-Dec. 1945): 89-101.

Cochran, Sherman. Chinese Medicine Men: Consumer Culture in China and Southeast Asia. Cambridge, MA: Harvard University Press, 2006.

“Death of Dr. Liu.” China News, August 30, 1961, 2.

Dikötter, Frank, Lars Laamann, and Zhou Xun. Narcotic Culture: A History of Drugs in China. London: Hurst, 2004.

Fang Xiaoping. Barefoot Doctors and Western Medicine in China. Rochester, NY: University of Rochester Press, 2012.

Florey, H.W., et al. "Further Observations on Penicillin.” Lancet 16 August 1941, 177-189.

Gross, Miriam. Farewell to the God of Plague: Chairman Mao's Campaign to Deworm China. Oakland, CA: University of California Press, 2016.

Guo Xingsun (S.S. Kwauk) 郭星孫. “A Simple Apparatus for Penicillin Aerosolization.” Chinese Medical Journal 67, no. 9 (Sept. 1949): 504-507.

Hvistendahl, Mara. “China Takes Aim at Rampant Antibiotic Resistance.” Science 336, no. 6083 (May 18, 2012): 795.

Jin Xinghua 金星华, ed., Gongheguo shaoshu minzu kexuejia chuan 共和国少数民族科学家 传 [Record of Ethnic Minority Scientists in the People’s Republic]. Guiyang: Guizhou minzu chubanshe, 2015.

King, Z. "Epidemic Prevention and Control in China." Chinese Medical Journal 61 (1943): 47-54.

Lee, Victoria. "Microbial Transformations: The Japanese Domestication of Penicillin Production, 1946-1951." Historical Studies in the Natural Sciences 48, no. 4 (Sept. 2018): 441-474.

Lin Shujin 林淑瑾 (Lin Shu-chin). “Penicillin in the Treatment of Empyema in Children.” Chinese Medical Journal 64, no. 3-4 (Mar.-Apr. 1946): 73-85.

Lin Zhaoqi (Chao-chi Ling) 林兆耆. “A Preliminary Study of the Treatment of Chinese Louse-Borne Relapsing Fever with Penicillin." Chinese Medical Journal 65, no. 7-8 (Jul. - Aug. 1947): 225-230.

Lou Wuji 娄无忌 and Zhou Xiangquan 周湘泉. “Fan Qingsheng 樊庆笙 (1911 - ).”In Zhongguo kexue jishu zhuanjia zhuanlüe, nongxue bian, turang juan 1 中国科学技术 专家传略, 农学编, 土壤卷 1 [Biographical Sketches of Chinese Experts in Science and Technology, Agronomy, Soil Science, Volume 1], edited by Zhongguo kexue jishu 
xiehui 中国科学技术协会 [China Association for Science and Technology], 192-197. Beijing: Zhongguo kexue jishu chubanshe, 1993.

Neushul, Peter. "Fighting Research: Army Participation in the Clinical Testing and Mass Production of Penicillin During the Second World War." In War, Medicine and Modernity, edited by Roger Cooter, Mark Harrison, and Steve Sturdy, 203-224. Stroud, UK: Sutton, 1998.

Niu Yahua 牛亚华, “20 shiji 40 niandai woguo de qingmeisu yanzhi gongzuo” 20 世纪 40 年 代我国的青霉素研制工作 [The Manufacture of Penicillin in China in the 1940s]. Zhonghua yishi zazhi 中华医史杂志 [Chinese Journal of Medical History] 31, no. 3 (2001): 184-188.

Niu Baocheng (Pao-ch'eng Niu) 牛寶成 and Liu Shihao (Shih-hao Liu) 劉士豪. “Penicillin in the Treatment of Putrid Lung Abscess." Chinese Medical Journal 67, no. 9 (Sept. 1949): 463-468.

Pruitt, Ida. “Six Years of Indusco.” Far Eastern Survey 14, no. 4 (Feb. 28, 1945): 48-52.

Rasmussen, Nicolas. “Of 'Small Men,' Big Science and Bigger Business: The Second World War and Biomedical Research in the United States." Minerva 40, no. 2 (2002): 115146.

Song Jie (Chieh Sung) 宋杰. “Intrathecal Administration of Penicillin: Case Reports with Discussion of Problems.” Chinese Medical Journal 66, no. 12 (Dec. 1948): 689-691. Soon, Wayne. "Blood, Soy Milk, and Vitality: The Wartime Origins of Blood Banking in China, 1943-45.” Bulletin of the History of Medicine 90, no. 3 (Fall 2016): 424-454. Soon, Wayne. "Coming from Afar: The Overseas Chinese and the Institutionalization of Western Medicine and Science in China, 1910-1970.” PhD diss., Princeton University, 2014.

Tang Feifan 汤飞凡. “Wu guo zi zhi qingmeisu de huigu yu qianzhan” 吾国自制青霉素的回 顾与前瞻 [Our Nation's Independent Production of Penicillin: Reflections and Outlook]. Kexue shijie 科学世界 [Science World] 18, no. 1-2 (1949): 3-5.

T’ang Fei-fan 汤飞凡 (Tang Feifan), Chang Hsiao-lou 张晓楼 (Zhang Xiaolou), Huang Yuan-t'ung 黃元桐 (Huang Yuantong), and Wang K'o-ch'ien 王克乾 (Wang Keqian). "Studies on the Etiology of Trachoma with Special Reference to Isolation of the Virus in Chick Embryo." Chinese Medical Journal 75, no. 6 (June 1957): 429-447. 
Wang Gaopeng 王高朋. “Qingmeisu zai jindai Zhongguo de chuanbo yu jieshou” 青霉素在 近代中国的传播与接受 [The Dissemination and Acceptance of Penicillin in Modern China]. MA diss., Hebei University, 2018.

Watt, John Robertson. Saving Lives in Wartime China: How Medical Reformers Built Modern Healthcare Systems amid War and Epidemics, 1928-1945. Leiden: Brill, 2014.

Wu Anran 吴安然 and Xie Shaowen 谢少文. “In Memory of Professor Tang Fei-fan.” Chinese Medical Journal 100, no. 6 (1987): 512-513.

Xu Dingding. "Experimental Production of Penicillin in Kunming in the Early 1940s." Protein \& Cell 4, no. 5 (May 2013): 323-324.

$\mathrm{Xu}$ Dingding 徐丁丁. “Kangri zhanzheng shiqi zhongyang fangyi chu de qingmeisu shizhi gongzuo”抗日战争时期中央防疫处的青霉素试制工作” [The Experimental

Production of Penicillin by the National Epidemic Prevention Bureau during the Second Sino-Japanese War]. Zhongguo keji shi zazhi 中国科技史杂志 [The Chinese Journal for the History of Science and Technology] 34, no. 3 (2013): 347-359.

Xu Jianping. "The Life and Work of Dr. Fan Qingsheng: A Pioneer in Antibiotics Research, Agricultural Microbiology, Systems Agriculture, and Agricultural Education in China.” Protein \& Cell 8, no. 8 (2017): 551-557.

Yip, Ka-che. "Disease and the Fighting Men: Nationalist Anti-Epidemic Efforts in Wartime China, 1937-1945." In China in the Anti-Japanese War, 1937-1945, edited by David P. Barrett and Larry N. Shyu, 171-188. New York: Peter Lang, 2001.

Yip, Ka-che. Health and National Reconstruction in Nationalist China: The Development of Modern Health Services, 1928-1937. Ann Arbor, MI: Association for Asian Studies, 1995.

Yongue, Julia. “The Introduction of American Mass Production Technology to Japan During the Occupation: The Case of Penicillin.” In Organizing Global Technology Flows: Institutions, Actors, and Processes, edited by Pierre-Yves Donzé and Shigehiro Nishimura, 213-229. New York: Routledge, 2014.

Zhang Changshao 张昌绍, Qingmeisu yu lianmeisu 青霉素与链霉素 [Penicillin and Streptomycin]. Chongqing: Xiandai yixue she, 1944.

Zhen Zhiya 甄志亚, ed. Zhongguo yixue shi 中国医学史 [A History of Medicine in China]. Beijing: Renmin chubanshe, 1991. 
Zhong Huilan (Huei-lan Chung) 钟惠澜, Zhang An (An Chang) 张安, Zhang Naichu (NaiCh'u Chang) 张乃初, Feng Shuilian (Shui-lien Feng) 冯水连, Lu Ruiping (Jui-ping Lu) 陆瑞萍, and Cao Yupu (Yu-pu Tsao) 曹玉璞. “The Efficacy of Penicillin in the Treatment of Noma Occurring in Kala-azar Patients." Chinese Medical Journal 67, no. 9 (Sept. 1949): 469-473.

Zhongguo yiyao baokan xiehui 中国医药报刊协会 [China Pharmaceutical Press Association] and Zhongguo yiyao gongye keyan kaifa cujin hui 中国医药工业科研开 发促进会 [China Pharmaceutical Industry Association for the Development and Promotion of Scientific Research], eds. Xin zhongguo yaopin jianguan yu fazhan jingdian huicui 新中国药品监管与发展经典荟萃 [Classic Compendium of Drug Regulation and Development in New China]. Beijing: Zhongguo yiyao keji chubanshe, 2011. 